\title{
Neuropathic Pain due to Small Fiber Neuropathy in Aging: Current Management and Future Prospects
}

\author{
Brigitte A. Brouwer ${ }^{1} \cdot$ Bianca T. A. de Greef ${ }^{2}$. \\ Janneke G. J. Hoeijmakers ${ }^{2} \cdot$ Margot Geerts $^{2}$ • \\ Maarten van Kleef ${ }^{1} \cdot$ Ingemar S. J. Merkies $^{2,3}$. \\ Catharina G. Faber ${ }^{2}$
}

Published online: 4 August 2015

(C) The Author(s) 2015. This article is published with open access at Springerlink.com

\begin{abstract}
Over the last 10 years, the diagnosis small fiber neuropathy (SFN) has gained recognition worldwide. Patients often suffer from severe neuropathic pain that may be difficult to treat. A substantial subset of patients with SFN is aged 65 years or older, and these patients often exhibit comorbidities and usage of multiple drugs, making neuropathic pain treatment more challenging. In this review, we highlight relevant pathophysiological aspects and discuss currently used therapeutic strategies for neuropathic pain. Possible pitfalls in neuropathic pain treatment in the elderly will be underlined.
\end{abstract}

\section{Key Points}

Treatment of neuropathic pain due to small fiber neuropathy may be challenging.

Comorbidity and polypharmacy are more frequent in the elderly, making treatment even more challenging.

Especially in the elderly, topical treatment may be considered as first-line treatment, whereas tricyclic antidepressants are best avoided.

Catharina G. Faber

c.faber@mumc.nl

1 Department of Anesthesiology and Pain Medicine, Maastricht University Medical Center, 6202 AZ Maastricht, The Netherlands

2 Department of Neurology, Maastricht University Medical Center, 6202 AZ Maastricht, The Netherlands

3 Department of Neurology, Spaarne Hospital, 2130 AT Hoofddorp, The Netherlands

\section{Introduction}

Small fiber neuropathy (SFN) is a peripheral neuropathy in which predominantly the unmyelinated C-fibers and thinly myelinated $\mathrm{A} \delta$-fibers are affected [1]. The diagnosis is based on clinical symptoms, reduced intra-epidermal nerve fiber density in skin biopsy, and/or abnormal temperature threshold tests [2-4], and no large nerve fiber involvement at physical examination or nerve conduction tests. The prevalence is at least 53 cases per 100,000 inhabitants, and the rates are higher in elderly patients [5]. Many conditions have been associated with SFN, such as diabetes mellitus, hyperlipidemia, amyloidosis, Fabry syndrome, celiac disease, sarcoidosis and other systemic illnesses, human immunodeficiency virus (HIV) infection, and hereditary sensory and autonomic neuropathies [3]. Recently, also pathogenic mutations in sodium channels $\left(\mathrm{Na}_{\mathrm{v}} 1.7, \mathrm{Na}_{\mathrm{v}} 1.8\right.$ and $\mathrm{Na}_{\mathrm{V}} 1.9$ ) were reported in patients with painful neuropathy [6]. Despite a comprehensive work-up of patients with SFN, in a substantial proportion (ranging from 24 to $93 \%$ in different series), no underlying cause can be identified [3].

SFN patients often suffer from devastating pain, and have a severely reduced quality of life [7]. In addition to the typical SFN-related complaints (neuropathic pain and autonomic symptoms such as dry mouth, dry eyes, micturation problems or bowel dysfunction), anxiety, depression, sleeping problems and fatigue may also influence quality-of-life expectations [8-10]. Pain severity is associated with a high use of medication, frequent physician consultations and substantial health care costs [10].

For the symptomatic treatment of neuropathic pain in SFN, mostly general guidelines are used [11-15]. Pharmacological treatment options mainly are antidepressants 
[16], anticonvulsants [17] and opioids [18], with generally disappointing results [14].

\section{Pathways in Neuropathic Pain}

Understanding pathways and mechanisms involved in the development of neuropathic pain is important to define possible therapeutic targets. Pain is defined as an unpleasant sensory and emotional experience associated with actual or potential tissue damage [19]. As the definition suggests, pain is a subjective phenomenon, and is difficult to catch in an objective outcome measure [20-23]. In humans, pain represents a final integrative package, consisting of neurophysiological processes as well as contextual, psychological, and sociocultural factors.

Neuropathic pain is caused by a lesion or disease that affects the somatosensory nervous system [19]. The thinly myelinated $\mathrm{A} \delta$-fibers and unmyelinated $\mathrm{C}$-fibers, predominantly involved in SFN [1-3], arise in the skin where they serve for the detection of cold, heat and, as nociceptors, detection of painful stimuli [24-26]. In addition, they fulfill an efferent function as part of the peripheral autonomic nervous system [3, 27]. Generally, nociceptors are electrically silent; after activation by noxious stimuli, an action potential is initiated and transported via peripheral axons to the cell bodies located in the trigeminal ganglia and in the dorsal root ganglia alongside the spinal column and medulla oblongata [6]. Via central axons, the signal is transmitted onward to synapse on second-order neurons in the central nervous system [24, 26]. Voltage-gated sodium, potassium and calcium channels, transient receptor potential channels and acid-sensing ion channels all contribute to the regulation of nociceptor excitability [24, 26, 28-30]. Recently, painful peripheral neuropathy has been linked to three different types of voltage-gated sodium channel (VGSC) mutations [6, 31-34].

Animal models and human studies have shown that nerve damage, such as in painful peripheral neuropathy, can result in pathological sensitization and ectopic impulse generation in primary afferent nociceptors with subsequent secondary changes in central processing [35]. Central sensitization is largely mediated by the $N$-methyl-D-aspartate (NMDA) receptor [36]. Activation of descending pathways [spinal norepinephrine pathway and the descending spinal serotonergic (5-HT) pathway] in the periaqueductal gray-rostral ventromedial medulla oblongata may also reduce pain transmission [37]. However, the system may also facilitate pain transmission, thereby contributing to chronic pain states [38-40].

\section{Small Fiber Neuropathy in the Elderly}

A substantial number of patients with SFN are 65 years or older. In our cohort of 598 patients diagnosed with SFN, diagnosed according to international criteria, at the Maastricht University Medical Center [2, 3], $19 \%$ were 65 years or older $(n=117)$. Most of these elderly patients had several comorbidities at first presentation (Fig. 1a). Only $11 \%(n=13)$ had no comorbidity (compared with $46 \%$ in patients $<65$ years; $X^{2}$ test, $\left.p<0.001\right)$. The most frequent concomitant disorders were hypertension (60\%), cardiovascular disease (44\%), immune-mediated diseases $(20 \%)$, malignancy $(16 \%)$ and diabetes mellitus (9\%). As a consequence, most patients used several drugs, on average four (Fig. 1b). Only $6 \%$ did not use any medication (compared with $26 \%$ in patients $<65$ years; $X^{2}$ test, $p<0.001)$.

The most frequently prescribed pain drugs in this group of elderly patients were anticonvulsants (pregabalin,
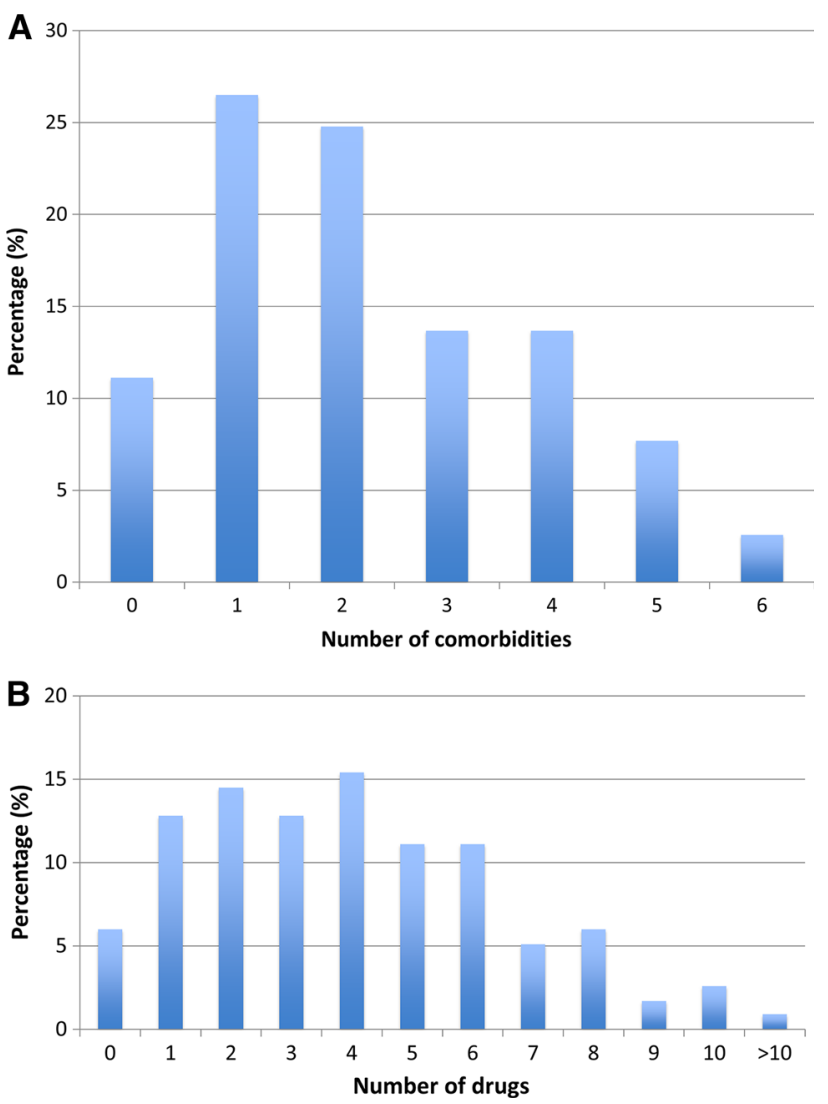

Fig. 1 Comorbidities and use of drugs in the elderly. a Number of comorbidities at initial presentation. b Number of drugs used at initial presentation in patients with SFN aged 65 years or older $(n=117)$. Concomitant disorders were hypertension $(60 \%)$, cardiovascular disease $(44 \%)$, immune-mediated diseases $(20 \%)$, malignancy $(16 \%)$ and diabetes mellitus (9\%). SFN small fiber neuropathy 
gabapentin, carbamazepine; $16 \%$ ), antidepressants (amitriptyline, duloxetine, nortriptyline, venlafaxine; $14 \%$ ), opioids (weak and strong opioids; $14 \%$ ), cyclooxygenase (COX) inhibitors (11\%) and acetaminophen $(12 \%)$.

The presence of comorbidity, polypharmacy and physiological changes (e.g., increased body fat, reduced muscle mass, reduction in body's fluid balance, decrease in renal and hepatic function) in older people increases the risk of side effects and poses a challenge in symptomatic drug treatment of neuropathic pain $[41,42]$.

\section{Pharmacological Management of Neuropathic Pain}

Several therapeutic strategies are commonly used for the treatment of neuropathic pain. Most pharmacological treatment regimens exist in three groups: antidepressants, anticonvulsants and opioids. However, less than $50 \%$ of patients achieve $50 \%$ of pain relief with currently available drugs [12, 14]. Most of the available analgesics act at different levels (e.g., sodium channels, noradrenergic system, opioidergic system) and are prescribed without any selection in terms of pathogenesis and etiology. Unfortunately, none of the new drugs have proven to be more effective than amitriptyline [12], an old antidepressant. Additional treatment strategies are topical treatments, such as capsaicin and lidocaine [14, 41], and transcutaneous electrical nerve stimulation (TENS) [43].

\subsection{Antidepressants}

Since the 1960s, antidepressants have been used for pain relief [44] and, nowadays, are mainly used for neuropathic pain treatment. Tricyclic antidepressants (TCAs) and serotonin-noradrenalin reuptake inhibitors (SNRIs) are generally considered first-line treatments for neuropathic pain $[12,14,15]$.

\subsubsection{Tricyclic Antidepressants}

TCAs were initially synthesized as antipsychotic drugs, but appeared to have an antidepressive trait [45, 46]. They are widely used for neuropathic pain and have a number needed to treat (NNT) of 3.6 [14]. TCAs are also known as dirty drugs because of their actions on multiple neurotransmitter receptors; they block reuptake of norepinephrine and VGSCs, and are antagonists of $\mathrm{H}_{1}$-histaminic, muscarinic cholinergic and $\alpha_{1}$-adrenergic receptors. Some TCAs inhibit serotonin reuptake or are antagonists of serotonin $2 \mathrm{~A}$ and $2 \mathrm{C}$ receptors [47-53]. Other presumed effects are anti-inflammatory, increasing and decreasing cytokine production, and potentiation of opioid analgesia [54-56]. TCAs may improve sleep disturbances and, in higher doses, have an antidepressive effect. The choice of a specific TCA is often influenced by the side-effect profile. Secondary amine TCAs (nortriptyline and desipramine) are preferred because they are better tolerated than tertiary amine TCAs (amitriptyline and imipramine) with comparable analgesic efficacy $[15,57$, 58].

\subsubsection{Serotonin-Noradrenalin Reuptake Inhibitors}

As their name already suggests, SNRIs have a dual monoamine mechanism that should lead to better efficacy; however, for neuropathic pain, SNRIs have an NNT of 6.4 [14]. SNRIs indirectly also lead to an increase of dopamine in the prefrontal cortex by blocking the norepinephrine transporters, which may modulate pain [59,60]. Venlafaxine and duloxetine are well studied drugs for neuropathic pain [14]. Duloxetine has a lower incidence of side effects than venlafaxine (such as hypertension, nausea and sexual dysfunction) $[15,61]$. Precautions are needed in liver dysfunction, severe kidney dysfunction, uncontrolled hypertension, and with venlafaxine in significant cardiac disease. Simultaneous use of other antidepressants and tramadol should be avoided.

\subsubsection{Antidepressants and the Elderly}

Age-associated morbidity can complicate treatment with antidepressants. Antidepressants are metabolized more slowly in the elderly, which can lead to a higher plasma drug level. The American Geriatrics Society (AGS) strongly recommends that TCAs should be avoided in older adults, because of the risk of adverse events, such as cardiac arrhythmia, somnolence, hypotension with increased risk of falls and injury, cognitive impairment, and anticholinergic side effects [62]. TCAs should certainly be dosed below $75 \mathrm{mg} /$ day in adults aged greater than 65 years [14].

\subsection{Anticonvulsants}

Anticonvulsant drugs have been used since the 1960s for pain management. They exhibit different mechanisms of action. Gabapentin and pregabalin are considered first-line treatment for neuropathic pain [12, 14, 15].

\subsubsection{Gabapentin and Pregabalin}

Gabapentin was initially designed in 1994 as an analog of GABA (as an antiepileptic drug), which could penetrate the blood-brain-barrier. In 1996, it became clear that gabapentin had a therapeutic effect on pain. Pregabalin, a chemically related amino-acid drug, was developed a few years later. 
Though gabapentin initially was assumed to have a GABA-mimetic effect, it turned out that gabapentin does not interact with GABA-A or -B receptors and does not influence GABA uptake [63]. Gabapentin and pregabalin both bind to voltage-gated $\alpha_{2} \delta$-calcium channel of $N$ type and P/Q type in the dorsal horn, but also on the level of the thalamus, periaqueductal gray and cortex [64]. These presynaptic voltage-sensitive calcium channels are involved in regulation of neurotransmitter release by firing synaptic vesicles into the synapse. Binding gabapentin or pregabalin blocks calcium influx and influences the release of presynaptic neurotransmitters, such as GABA, glutamate, acetylcholine, substance $P$ and monoamines [65-68].

Gabapentin has an NNT of 7.2 for neuropathic pain, and pregabalin an NNT of 7.7 [14]. Gabapentin and pregabalin both have no clinically important drug-drug interactions. Gabapentin dose titration may take several weeks, whereas the starting dose of pregabalin of $75 \mathrm{mg}$ twice daily is already efficacious [15]. The potential for twice-daily dosing and the linear pharmacokinetics leading to a predictable dose-response relationship of pregabalin may be an advantage in the ease of use of this drug.

Side effects of gabapentin and pregabalin are somnolence, dizziness, ataxia, edema and tremor. Pregabalin increases slow wave sleep and total sleep duration in patients with pain [69], and can also be used for generalized anxiety disorders. Both drugs require dosage reduction in patients with renal impairment [70].

\subsubsection{Other Antiepileptic Drugs}

Several other antiepileptic drugs, such as topiramate, zonisamide, and oxcarbazepine or carbamazepine, have been studied for neuropathic pain, though most studies were negative [14], and therefore these drugs are not recommended as first-line treatment.

\subsubsection{Anticonvulsants and the Elderly}

Gabapentin or pregabalin are usually well tolerated if titrated appropriately. Treatment should start with the lowest possible dose and be increased very slowly on the basis of response and side effects, such as somnolence, dizziness, ataxia and peripheral edema [71]. Gabapentin can cause or exacerbate cognitive or gait impairment. Dose reduction in patients with renal dysfunction is needed [70]. Furthermore, antiepileptic drugs may lead to an increased risk of falling [71].

\subsection{Opioids}

Opioids refer to all substances that produce morphine-like effects that are blocked by antagonists such as naloxone, and can be produced synthetically or endogenously. Opioids have a well defined role in the treatment of cancer pain; however, their role in the long-term treatment of nonmalignant pain is controversial because of concerns about tolerability, the development of tolerance to the analgesic effect, and addiction [72]. Furthermore, side effects occurred in about $50 \%$ of patients treated for chronic nonmalignant pain, and more than $20 \%$ discontinued treatment because of adverse events [73, 74]. Opioids can be effective in neuropathic pain, with an NNT of 4.7 for tramadol and 4.3 for strong opioids [14, 75], and are considered second- and third-line treatments [12, 14, 15].

Opioids produce analgesia by acting on opioid receptors in peripheral afferent neurons, dorsal horn of the spinal cord, brainstem and the brain. The opioid receptors are $\mathrm{G}$ protein-coupled receptors and are classified as $\mathrm{mu}$ (MOP), delta (DOP) and kappa (KOP) and a fourth nonclassical opioid receptor for nociceptin/orphanin FQ (NOP) [76, 77]. The receptor pharmacology is complex; the cellular response does not only depend on the ligand and the type of receptor, but also on the cellular environment of the receptor [78, 79]. After activation of the receptor, a portion of the $G$ protein is released, and leads to inhibition of cyclic adenosine monophosphate (AMP), with consequent alteration of protein phosphorylation. Cyclic AMP acts as a second messenger within the cell, resulting in the activation of protein kinases (short-term effects) and gene transcription proteins and/or gene transcription (long-term effects) [80]. Opioid receptors located on the presynaptic terminals of the nociceptive $\mathrm{C}$ - and A-fibers can be activated by an opioid agonist, which will indirectly inhibit voltage-gated calcium channels, decreasing cyclic AMP levels and blocking the release of pain neurotransmitters such as glutamate, substance $\mathrm{P}$, and calcitonin gene-related peptide [80]. Furthermore, opioids activate presynaptic receptors on GABA neurons, which inhibit the release of GABA in the ventral tegmental area, indirectly leading to an increase in dopamine. The latter plays a role in the development of addiction.

One of the most common side effects is constipation, which requires prophylaxis [72]. Other side effects are pruritus, dizziness, nausea and vomiting, sedation, impaired concentration, and ataxia. The risk of respiratory depression should be weighed in patients with an underlying pulmonary condition or receiving concomitant central nervous system drugs associated with hypoventilation. Not all opioids show equal effects on respiratory depression. Long-term use of opioids can lead to hypogonadism and immunological changes. Prolonged opioid use may lead to tolerance (the need to increase the dose to maintain pain relief) and opioid-induced hyperalgesia [81, 82]. Rotation from one strong opioid to another can restore not only analgesia, but also cause other side effects [83, 84]. 
One of the biggest concerns is addiction due to prolonged opioid use, with high health and economic costs and potentially fatal consequences $[85,86]$.

Increasing opioid doses are strongly related to large increases in risk of overdose morbidity and mortality, with a substantially increased risk associated with doses at or above $100-120 \mathrm{mg}$ morphine-equivalent dose per day [86]. Moreover, disordered breathing during nonREM sleep increases with dose. Therefore, opioid therapy should be part of a multifaceted approach to pain management [86], and clinicians should be alert for behavior suggestive of addiction, such as frequent change of doctors, non-compliance, and reports of lost prescriptions [85].

\subsubsection{Weak Opioids}

4.3.1.1 Tramadol Tramadol, a second-line treatment, is a weak opioid receptor agonist and a norepinephrine and serotonin (5-HT)-reuptake inhibitor, and has an NNT of 4.7 [14]. Special precautions should be taken with patients with asthma, epilepsy, and severe liver and renal impairment. It has interactions with most antidepressant drugs.

\subsubsection{Strong Opioids}

Strong opioids are considered third-line treatment, and have an NNT of 4.3 [14].
4.3.2.1 Transdermal Buprenorphine Buprenorphine is a semisynthetic non-selective mixed opioid agonist-antagonist and can bind to the three classical and the non-classical opioid receptors. The anti-nociceptive effect is primarily exerted via the mu-receptor and is attenuated by the nociception receptor. No specific adjustments have to be made in kidney impairment. Excretion is mainly by the liver, and liver impairment can prolong the half-life, however, without clinical relevance, because of low-activity metabolites. Precautions should be taken in patients with asthma or chronic obstructive pulmonary disease (COPD). When rotating from a pure agonist, withdrawal symptoms can occur because Buprenorphine is a partial mu-agonist [87].

4.3.2.2 Oxycodone Sustained-Release Oxycodone is an agonist for the mu- and kappa-receptor. Oxycodone has similar efficacy to morphine and is usually well tolerated. It frequently causes constipation. Oxycodone has multiple active metabolites that may accumulate in renal dysfunction [87].

4.3.2.3 Fentanyl Patch Fentanyl is an opioid agonist. The vast majority of the metabolites-around $75 \%$-are eliminated in the urine. In cases of renal impairment, the clearance of fentanyl is reduced and the terminal half-life of the drug is prolonged. The clinical significance of this is not known [87]. In liver impairment, adjustment of dose may be required, though no specific guideline is available.

Table 1 Practical tips for the best treatment strategy for small fiber neuropathy in the elderly

Practical tips for the clinician

Always make the best choice considering safety and tolerability, strive for tailor-made therapy and individualization of care in clinical practice Local treatment In case of focal pain distribution or systemic contra-indications

Medication Take a careful medication history

Ask for previous adverse effects, inadequate effects, inadequate dose

Check for comorbidity such as liver and kidney impairment

Check potential interactions with other drugs, herbs, caffeine, smoking, grapefruit

Adjust dose if necessary

Consider genetic testing in patients with a history of many side effects

Make patient also responsible for medication history by handing out a form for medication

Opioids Avoid instant-release opioids

Start strong opioids only as third-line treatment

Be aware of the potential risks

Social context Ask for impact on sleep, work, daily functioning, relationship, and anxiety, and treat when possible

Age

Avoid polypharmacy as much as possible

Strive for treatment with the least side effects

Always start low, go slow!

AND if nothing works consider multi-targeting! 


\section{Treatment Algorithm for SFN in elderly}

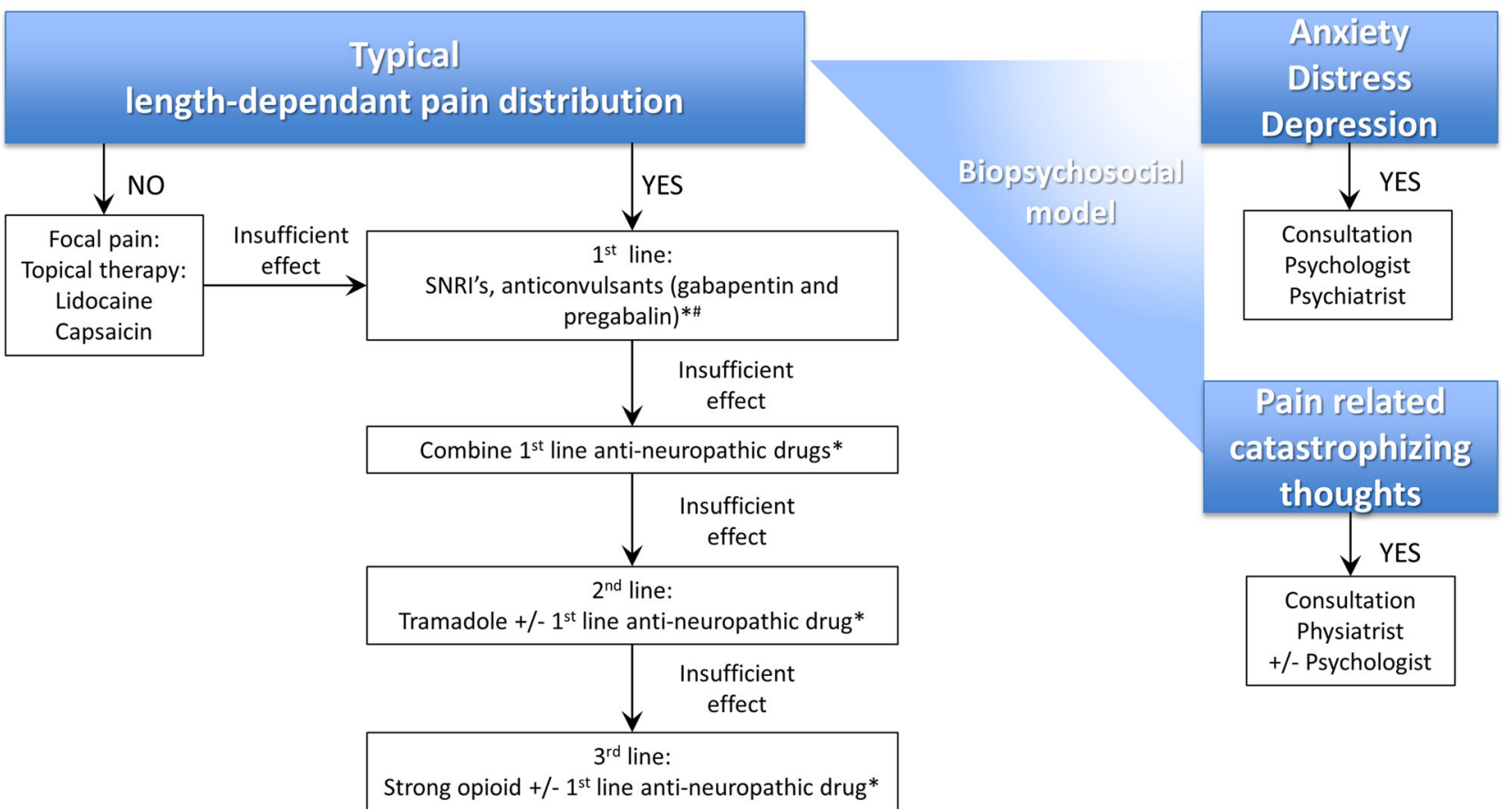

Fig. 2 Treatment algorithm for SFN in the elderly. In addition to physical factors, psychological, neurophysiological, socio-economic and cultural aspects may influence the experience and maintain pain; a multidisciplinary approach in line with the biopsychosocial model is required in optimizing treatment for the individual patient [41]. Asterisks see also Fig. 3 (contra-indication algorithm for drugs prescription) and Table 1 (Practical tips for the best treatment

4.3.2.4 Methadone Methadone is a synthetic opioid (mu agonist), a weak NMDA receptor antagonist and a serotonin-reuptake inhibitor. No adjustments have to be made in kidney impairment. In serious liver failure, the use of methadone is contraindicated. Methadone can have a long and variable half-life time. Variation of half-life is $8-80 \mathrm{~h}$, with a risk of accumulation. It has potential interactions with multiple drugs. Furthermore, it may cause prolongation of the QT-time interval [88], and ECG screening or monitoring may be considered.

\subsubsection{Opioids and the Elderly}

Although older people tend to require lower doses than younger individuals, opioid effects do not appear to vary with age [89]. Though short-term efficacy of opioid use ( $\leq 12$ weeks) among older adults has been established, almost half of the patients discontinued the medication, strategy for SFN in the elderly). Hash in contrast with first-line neuropathic pain treatment in adults $<65$ years, TCAs should be avoided in older adults, because of the risk of adverse events, such as cardiac arrhythmia, somnolence, hypotension with increased risk of falls and injury, cognitive impairment, and anticholinergic side effects [62]. SFN small fiber neuropathy, SNRI serotonin-noradrenalin reuptake inhibitor, $T C A$ tricyclic antidepressant

mostly because of intolerable side effects [90]. There is limited evidence in support of long-term opioid treatment $[86,91]$. In the elderly, the half-life time of the active drug and its metabolites is increased, but not in buprenorphine, making it a relative safe choice in the elderly [87]. Furthermore, buprenorphine does not have a dose-dependent decrease in respiration $[92,93]$. In elderly patients with impaired hepatic and renal function, there is the risk of accumulation of metabolites from certain opioids, such as morphine.

Given the established risks associated with opioid use, such as hospital admission, mortality and fractures [94], the potential negative effects must be carefully weighed and be used as part of an integrated treatment program, including functional and psychosocial modalities [87, 94]. Methadone should only be prescribed by clinicians who have considerable experience with the drug, or in closely monitored settings, because of difficulty in titration [62]. 


\subsection{Topical Analgesic Agents}

Topical administration may be better tolerated than other routes of administration. However, the efficacy of topical lidocaine and capsaicin in the management of localized neuropathic pain is limited, and therefore these drugs are considered second-line treatment $[14,41]$.

\subsubsection{Capsaicin}

Capsaicin is the primary component in hot peppers that gives the highly strong spicy flavor. Topical capsaicin is available in cream with low-concentration capsaicin $(0.025-0.075 \%)$ and transdermal patches with high-concentration capsaicin $(8 \%)$. Capsaicin can only be used when the skin is intact and has no interaction with other medication. There are minimal systemic side effects (hypertension, first-degree atrioventricular block, coughing, nausea). Local side effects are erythema, burning pain and itch. Topical treatment with capsaicin can cause reversible degeneration of epidermal nerve fibers. The long-term safety of repeated applications of high-concentration capsaicin patches, particularly with respect to this epidermal nerve fiber degeneration, is unknown [14].

\subsubsection{Lidocaine $5 \%$ Medicated Plaster}

Topical lidocaine has been used for both acute and chronic pain treatments. The effect of the lidocaine plaster is based on two actions. The plaster itself provides a cooling perception and mechanical protection [95-97]. Additionally, lidocaine is a VGSC inhibitor, which stabilizes the neuronal membrane potential of $\mathrm{A} \delta$ - and $\mathrm{C}$-fibers. This pharmacological action results in a reduction of pain and allodynia [98]. The $5 \%$ lidocaine-medicated plaster has minimal systemic absorption of the active substance [99], with a low risk of toxicity and a lack of drug-drug interactions [100]. Although the absorption of the skin is extremely low, caution is needed in patients with class 1 antiarrhythmic drugs or other local anesthetics.

\subsubsection{Topical Agents and the Elderly}

Lidocaine patch and high-concentration capsaicin patches are considered second-line treatment because of low effect sizes. However, lidocaine patches may be considered as a first-line drug in case of side effects or safety of other firstline treatments, particularly in elderly patients [14].

\section{Complementary Therapies}

\subsection{Transcutaneous Electrical Nerve Stimulation}

TENS is the application of electrical stimulation of varying frequency, intensity and pulse duration to the skin for pain relief [101]. TENS is generally believed to be a safe noninvasive intervention. However, the effectiveness of TENS in chronic pain has not been established with certainty [43].

\subsection{TENS and the Elderly}

Age does not have a significant impact on pain or TENS comfort, though age-related changes might limit the use of TENS among the older population [41, 102].

\section{Multifaceted Neuropathic Pain Management in the Elderly}

Managing neuropathic pain in the elderly is often complex because of its multifactorial facets. The neurobiology of aging, its relation to pain, changes in pharmacokinetics, drug metabolism, and body composition, polypharmacy and cognitive and affective factors may influence pain expression and pain management in the elderly [103].

Individual drugs have $50 \%$ of pain relief, with an NNT of 4-10, meaning that the outcome of drug treatment is, at best, moderate [14, 104]. Multifaceted therapy is often needed to address the various pain conditions, whereas older people may be particularly susceptible to side effects and drug interactions. A practical approach is presented in Table 1 and Figs. 2 and 3.

In general, medication should be started in a low dose and titrated slowly. TCAs should be avoided in the elderly if possible, or at least not be prescribed above $75 \mathrm{mg} /$ day. A therapeutic trial should be of adequate length to assess efficacy, and the dose needs to be adjusted if side effects become burdensome, with a slower titration curve to attain therapeutic levels if needed [62, 103]. It is important to optimize one regimen first, and then gradually add agents, if needed. Therapies which have overlapping pharmacodynamics or that may have an adverse pharmacokinetic interaction, such as metabolic inhibitors, should not be combined. Especially in older patients, attention is needed regarding agents acting within the central nervous system. Therapy should be tapered down over time, if possible, to attain the lowest effective maintenance dose. 
Contra-indication Algorithm for drugs prescription

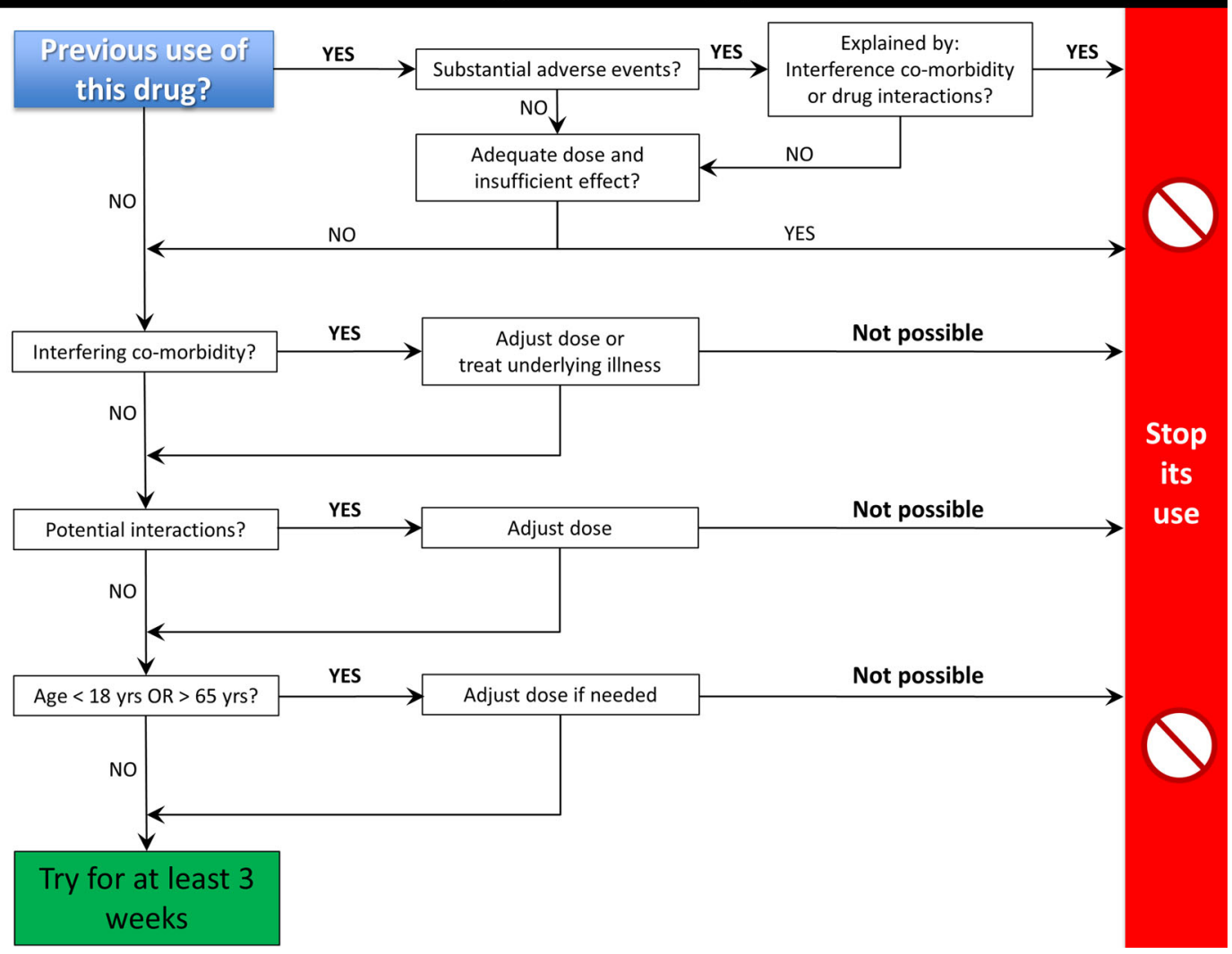

Fig. 3 Contra-indication algorithm for drugs prescription. For every drug considered, it is advisable to go through these steps to make a deliberate decision. Be aware of comorbidities such as kidney and liver impairment or cardiac disease. Yrs years

\section{Discussion and Future Perspectives}

In general, the treatment of chronic neuropathic pain is complicated and multidimensional. The mechanisms underlying its occurrence and chronification, as well as the inter-individual variability, remain poorly understood. As a consequence, symptomatic and unspecific treatments are frequently the only available therapeutic options. Indeed, all the clinical trials carried out in the last 20 years provided similar results, accounting for $50 \%$ of pain relief in $50 \%$ of patients at best $[12,14]$. Efficacious and tailored treatments for neuropathic pain are the ultimate target both for patients and scientists. The discovery of gain-of-function $\mathrm{Na}_{\mathrm{V}} 1.7, \mathrm{Na}_{\mathrm{V}} 1.8$ and $\mathrm{Na}_{\mathrm{V}} 1.9$ mutations in painful peripheral neuropathy has expanded the spectrum of painful sodium channelopathies [6, 34]. It provides a better understanding of the pathogenetic mechanisms and may provide targets for potential treatment with the expectation of fewer side effects [105-107]. Genetics may also play a role in drug response. For some drugs, pharmacogenetics can predict the efficacy and toxicity of treatment at the individual level [108-110].
As pain is a complex symptom, in which not only physical factors but also psychological, neurophysiological, socioeconomic and cultural aspects may influence the experience and continuation of pain, a multidisciplinary approach in line with the biopsychosocial model is required in optimizing treatment for the individual patient (Fig. 2) [41]. Psychological techniques may be helpful, not just when pharmacological therapy is ineffective, but as an adjunct to medication or as a first-line therapy if the patient prefers. Moreover, chronic pain often has coexisting symptoms, such as depression, anxiety and sleep deprivation, and focusing on relief of these symptoms may be crucial for patients.

\section{Compliance with Ethical Standards}

Funding C. Faber and I. Merkies received grants from the European Union 7th Framework Programme (grant $n^{\circ} 602273$ ) and from the Prinses Beatrix Spierfonds (W.OR12-01).

Conflicts of interest $\quad$ B. A. Brouwer reports no disclosures. B. T. A. de Greef reports no disclosures. J. G. J. Hoeijmakers reports no disclosures. M. Geerts reports no disclosures. M. van Kleef reports no disclosures. I. S. J. Merkies participated in steering committees of the Talecris ICE Study, CSL Behring, LFB, Novartis and Octapharma (a research foundation at the University of Maastricht received the 
honoraria on behalf of Dr. Merkies); received travel funding from Talecris for presentations on the ICE trial; and received funding from the GBS/CIDP Foundation International. C. G. Faber reports grants from Grifols and Lamepro.

Open Access This article is distributed under the terms of the Creative Commons Attribution-NonCommercial 4.0 International License (http://creativecommons.org/licenses/by-nc/4.0/), which permits any noncommercial use, distribution, and reproduction in any medium, provided you give appropriate credit to the original author(s) and the source, provide a link to the Creative Commons license, and indicate if changes were made.

\section{References}

1. England JD, Asbury AK. Peripheral neuropathy. Lancet. 2004;363(9427):2151-61.

2. Lauria G, Merkies IS, Faber CG. Small fibre neuropathy. Curr Opin Neurol. 2012;25(5):542-9.

3. Hoeijmakers JG, Faber CG, Lauria G, Merkies IS, Waxman SG. Small-fibre neuropathies-advances in diagnosis, pathophysiology and management. Nat Rev Neurol. 2012;8(7):369-79.

4. Tesfaye S, Boulton AJ, Dyck PJ, Freeman R, Horowitz M, Kempler P, et al. Diabetic neuropathies: update on definitions, diagnostic criteria, estimation of severity, and treatments. Diabetes Care. 2010;33(10):2285-93.

5. Peters MJ, Bakkers M, Merkies IS, Hoeijmakers JG, van Raak EP, Faber CG. Incidence and prevalence of small-fiber neuropathy: a survey in the Netherlands. Neurology. 2013;81(15):1356-60.

6. Hoeijmakers JG, Faber CG, Merkies IS, Waxman SG. Painful peripheral neuropathy and sodium channel mutations. Neurosci Lett. 2015;596:51-9.

7. Bakkers M, Faber CG, Hoeijmakers JG, Lauria G, Merkies IS. Small fibers, large impact: quality of life in small-fiber neuropathy. Muscle Nerve. 2014;49(3):329-36.

8. Poliakov I, Toth C. The impact of pain in patients with polyneuropathy. Eur J Pain. 2011;15(10):1015-22.

9. Lindh J, Tondel M, Persson B, Vrethem M. Health-related quality of life in patients with cryptogenic polyneuropathy compared with the general population. Disabil Rehabil. 2011;33(7):617-23.

10. Schaefer C, Mann R, Sadosky A, Daniel S, Parsons B, Nalamachu $\mathrm{S}$, et al. Health status, function, productivity, and costs among individuals with idiopathic painful peripheral neuropathy with small fiber involvement in the United States: results from a retrospective chart review and cross-sectional survey. J Med Econ. 2014;17(6):394-407.

11. Hovaguimian A, Gibbons $\mathrm{CH}$. Diagnosis and treatment of pain in small-fiber neuropathy. Curr Pain Headache Rep. 2011;15(3):193-200.

12. Attal N, Cruccu G, Baron R, Haanpaa M, Hansson P, Jensen TS, et al. EFNS guidelines on the pharmacological treatment of neuropathic pain: 2010 revision. Eur J Neurol. 2010;17(9):1113e88.

13. Haanpaa M, Attal N, Backonja M, Baron R, Bennett M, Bouhassira D, et al. NeuPSIG guidelines on neuropathic pain assessment. Pain. 2011;152(1):14-27.

14. Finnerup NB, Attal N, Haroutounian S, McNicol E, Baron R, Dworkin $\mathrm{RH}$, et al. Pharmacotherapy for neuropathic pain in adults: a systematic review and meta-analysis. Lancet Neurol. 2015;14(2):162-73.

15. Dworkin RH, O'Connor AB, Backonja M, Farrar JT, Finnerup NB, Jensen TS, et al. Pharmacologic management of neuropathic pain: evidence-based recommendations. Pain. 2007;132(3):237-51.

16. Saarto T, Wiffen PJ. Antidepressants for neuropathic pain. Cochrane Database Syst Rev. 2007(4):CD005454.

17. Goodyear-Smith F, Halliwell J. Anticonvulsants for neuropathic pain: gaps in the evidence. Clin J Pain. 2009;25(6):528-36.

18. Eisenberg E, McNicol E, Carr DB. Opioids for neuropathic pain. Cochrane Database Syst Rev. 2006(3):CD006146.

19. Treede RD, Jensen TS, Campbell JN, Cruccu G, Dostrovsky JO, Griffin JW, et al. Neuropathic pain: redefinition and a grading system for clinical and research purposes. Neurology. 2008;70(18):1630-5.

20. Farrar JT, Young JP Jr, LaMoreaux L, Werth JL, Poole RM. Clinical importance of changes in chronic pain intensity measured on an 11-point numerical pain rating scale. Pain. 2001;94(2):149-58.

21. Dworkin RH, Turk DC, Wyrwich KW, Beaton D, Cleeland CS, Farrar JT, et al. Interpreting the clinical importance of treatment outcomes in chronic pain clinical trials: IMMPACT recommendations. J Pain. 2008;9(2):105-21.

22. Forouzanfar T, Weber WE, Kemler M, van Kleef M. What is a meaningful pain reduction in patients with complex regional pain syndrome type 1? Clin J Pain. 2003;19(5):281-5.

23. Galer BS, Jensen MP. Development and preliminary validation of a pain measure specific to neuropathic pain: the Neuropathic Pain Scale. Neurology. 1997;48(2):332-8.

24. Dubin AE, Patapoutian A. Nociceptors: the sensors of the pain pathway. J Clin Invest. 2010;120(11):3760-72.

25. Lauria G, Merkies ISJ, Waxman SG, Faber CG. Epidermal nerve fibers. In: Aminoff MJ, Daroff RB, editors. Encyclopedia of the Neurological Sciences. 2nd ed. Oxford: Academic Press; 2014. p. 76-9.

26. Woolf CJ, Ma Q. Nociceptors-noxious stimulus detectors. Neuron. 2007;55(3):353-64.

27. Holzer P, Maggi CA. Dissociation of dorsal root ganglion neurons into afferent and efferent-like neurons. Neuroscience. 1998;86(2):389-98.

28. Lee Y, Lee $\mathrm{CH}, \mathrm{Oh} \mathrm{U}$. Painful channels in sensory neurons. Mol Cells. 2005;20(3):315-24.

29. Aurilio C, Pota V, Pace MC, Passavanti MB, Barbarisi M. Ionic channels and neuropathic pain: physiopathology and applications. J Cell Physiol. 2008;215(1):8-14.

30. Waxman SG, Zamponi GW. Regulating excitability of peripheral afferents: emerging ion channel targets. Nat Neurosci. 2014;17(2):153-63.

31. Faber CG, Hoeijmakers JG, Ahn HS, Cheng X, Han C, Choi JS, et al. Gain of function $\mathrm{Na}_{\mathrm{V}} 1.7$ mutations in idiopathic small fiber neuropathy. Ann Neurol. 2012;71(1):26-39.

32. Faber CG, Lauria G, Merkies IS, Cheng X, Han C, Ahn HS, et al. Gain-of-function Nav1.8 mutations in painful neuropathy. Proc Natl Acad Sci USA. 2012;109(47):19444-9.

33. Huang J, Han C, Estacion M, Vasylyev D, Hoeijmakers JG, Gerrits MM, et al. Gain-of-function mutations in sodium channel $\mathrm{Na}(\mathrm{v}) 1.9$ in painful neuropathy. Brain. 2014;137(Pt 6): $1627-42$.

34. Brouwer BA, Merkies IS, Gerrits MM, Waxman SG, Hoeijmakers JG, Faber CG. Painful neuropathies: the emerging role of sodium channelopathies. J Peripher Nerv Syst. 2014;19(2):53-65.

35. Baron R. Peripheral neuropathic pain: from mechanisms to symptoms. Clin J Pain. 2000;16(2 Suppl):S12-20.

36. Gilron I, Watson CP, Cahill CM, Moulin DE. Neuropathic pain: a practical guide for the clinician. CMAJ. 2006;175(3):265-75.

37. Porreca F, Ossipov MH, Gebhart GF. Chronic pain and medullary descending facilitation. Trends Neurosci. 2002;25(6):319-25. 
38. Suzuki R, Rygh LJ, Dickenson AH. Bad news from the brain: descending 5-HT pathways that control spinal pain processing. Trends Pharmacol Sci. 2004;25(12):613-7.

39. Vanegas H, Schaible HG. Descending control of persistent pain: inhibitory or facilitatory? Brain Res Brain Res Rev. 2004;46(3):295-309.

40. Ossipov MH, Dussor GO, Porreca F. Central modulation of pain. J Clin Invest. 2010;120(11):3779-87.

41. Abdulla A, Adams N, Bone M, Elliott AM, Gaffin J, Jones D, et al. Guidance on the management of pain in older people. Age Ageing. 2013;42(Suppl 1):i1-57.

42. Fine PG. Treatment guidelines for the pharmacological management of pain in older persons. Pain Med. 2012;13(Suppl 2):S57-66.

43. Nnoaham KE, Kumbang J. Transcutaneous electrical nerve stimulation (TENS) for chronic pain. Cochrane Database Syst Rev. 2008(3):CD003222.

44. Webb HE, Lascelles RG. Treatment of facial and head pain associated with depression. Lancet. 1962;1(7225):355-6.

45. Crisp AH, Hays P, Carter A. Three amine-oxidase inhibitor drugs in the treatment of depression; relative value and toxic effects. Lancet. 1961;1(7167):17-8.

46. Straker M. Imipramine (tofranil): a safe, effective antidepressant drug in private practice. Can Med Assoc J. 1959;80(7):546-9.

47. Pancrazio JJ, Kamatchi GL, Roscoe AK, Lynch C 3rd. Inhibition of neuronal $\mathrm{Na}^{+}$channels by antidepressant drugs. J Pharmacol Exp Ther. 1998;284(1):208-14.

48. Wang GK, Russell C, Wang SY. State-dependent block of voltage-gated $\mathrm{Na}^{+}$channels by amitriptyline via the local anesthetic receptor and its implication for neuropathic pain. Pain. 2004;110(1-2):166-74.

49. Nyback HV, Walters JR, Aghajanian GK, Roth RH. Tricyclic antidepressants: effects on the firing rate of brain noradrenergic neurons. Eur J Pharmacol. 1975;32(02):302-12.

50. Taylor JE, Richelson E. High affinity binding of tricyclic antidepressants to histamine H1-receptors: fact and artifact. Eur J Pharmacol. 1980;67(1):41-6.

51. Richelson E. Tricyclic antidepressants and histamine H1 receptors. Mayo Clin Proc. 1979;54(10):669-74.

52. Weinstock M, Cohen D. Tricyclic antidepressant drugs as antagonists of muscarinic receptors in sympathetic ganglia. Eur J Pharmacol. 1976;40(2):321-8.

53. Bohman B, Halaris A, Karbowski M. Effects of tricyclic antidepressants on muscarinic cholinergic receptor binding in mouse brain. Life Sci. 1981;29(8):833-41.

54. Gurgel JA, Lima-Junior RC, Rabelo CO, Pessoa BB, Brito GA, Ribeiro RA. Amitriptyline, clomipramine, and maprotiline attenuate the inflammatory response by inhibiting neutrophil migration and mast cell degranulation. Rev Bras Psiquiatr. 2013;35(4):387-92.

55. Munzer A, Sack U, Mergl R, Schonherr J, Petersein C, Bartsch $\mathrm{S}$, et al. Impact of antidepressants on cytokine production of depressed patients in vitro. Toxins (Basel). 2013;5(11):2227-40.

56. Bohn LM, Xu F, Gainetdinov RR, Caron MG. Potentiated opioid analgesia in norepinephrine transporter knock-out mice. J Neurosci. 2000;20(24):9040-5.

57. Watson CP, Vernich L, Chipman M, Reed K. Nortriptyline versus amitriptyline in postherpetic neuralgia: a randomized trial. Neurology. 1998;51(4):1166-71.

58. Kishore-Kumar R, Max MB, Schafer SC, Gaughan AM, Smoller B, Gracely RH, et al. Desipramine relieves postherpetic neuralgia. Clin Pharmacol Ther. 1990;47(3):305-12.

59. Blier P, Briley M. The noradrenergic symptom cluster: clinical expression and neuropharmacology. Neuropsychiatr Dis Treat. 2011;7(Suppl 1):15-20.
60. Dang YH, Xing B, Zhao Y, Zhao XJ, Huo FQ, Tang JS, et al. The role of dopamine receptors in ventrolateral orbital cortexevoked antinociception in a rat formalin test model. Eur $\mathbf{J}$ Pharmacol. 2011;657(1-3):97-103.

61. Stahl SM, Grady MM, Moret C, Briley M. SNRIs: their pharmacology, clinical efficacy, and tolerability in comparison with other classes of antidepressants. CNS Spectr. 2005;10(9):732-47.

62. American Geriatrics Society Panel on the Pharmacological Management of Persistent Pain in Older Persons. Pharmacological management of persistent pain in older persons. Pain Med. 2009;10(6):1062-83.

63. Bryans JS, Wustrow DJ. 3-substituted GABA analogs with central nervous system activity: a review. Med Res Rev. 1999;19(2):149-77.

64. Taylor CP, Garrido R. Immunostaining of rat brain, spinal cord, sensory neurons and skeletal muscle for calcium channel alpha2-delta (alpha2-delta) type 1 protein. Neuroscience. 2008;155(2):510-21.

65. Micheva KD, Taylor CP, Smith SJ. Pregabalin reduces the release of synaptic vesicles from cultured hippocampal neurons. Mol Pharmacol. 2006;70(2):467-76.

66. Joshi I, Taylor CP. Pregabalin action at a model synapse: binding to presynaptic calcium channel alpha2-delta subunit reduces neurotransmission in mice. Eur $\mathrm{J}$ Pharmacol. 2006;553(1-3):82-8.

67. Fehrenbacher JC, Taylor CP, Vasko MR. Pregabalin and gabapentin reduce release of substance $\mathrm{P}$ and CGRP from rat spinal tissues only after inflammation or activation of protein kinase $\mathrm{C}$. Pain. 2003; 105(1-2):133-41.

68. Taylor CP, Angelotti T, Fauman E. Pharmacology and mechanism of action of pregabalin: the calcium channel alpha2-delta (alpha2-delta) subunit as a target for antiepileptic drug discovery. Epilepsy Res. 2007;73(2):137-50.

69. Roth T, van Seventer R, Murphy TK. The effect of pregabalin on pain-related sleep interference in diabetic peripheral neuropathy or postherpetic neuralgia: a review of nine clinical trials. Curr Med Res Opin. 2010;26(10):2411-9.

70. Hanlon JT, Aspinall SL, Semla TP, Weisbord SD, Fried LF, Good CB, et al. Consensus guidelines for oral dosing of primarily renally cleared medications in older adults. J Am Geriatr Soc. 2009;57(2):335-40.

71. Pickering G. Antiepileptics for post-herpetic neuralgia in the elderly: current and future prospects. Drugs Aging. 2014;31(9):653-60.

72. Labianca R, Sarzi-Puttini P, Zuccaro SM, Cherubino P, Vellucci R, Fornasari D. Adverse effects associated with non-opioid and opioid treatment in patients with chronic pain. Clin Drug Investig. 2012;32(Suppl 1):53-63.

73. Moore RA, McQuay HJ. Prevalence of opioid adverse events in chronic non-malignant pain: systematic review of randomised trials of oral opioids. Arthritis Res Ther. 2005;7(5):R1046-51.

74. Noble M, Treadwell JR, Tregear SJ, Coates VH, Wiffen PJ, Akafomo $\mathrm{C}$ et al. Long-term opioid management for chronic noncancer pain. Cochrane Database Syst Rev. 2010(1):CD006605.

75. Zochodne DW, Max MB. An old acquaintance: opioids in neuropathic pain. Neurology. 2003;60(6):894-5.

76. Dietis N, Rowbotham DJ, Lambert DG. Opioid receptor subtypes: fact or artifact? Br J Anaesth. 2011;107(1):8-18.

77. Satoh M, Minami M. Molecular pharmacology of the opioid receptors. Pharmacol Ther. 1995;68(3):343-64.

78. Brady AE, Limbird LE. G protein-coupled receptor interacting proteins: emerging roles in localization and signal transduction. Cell Signal. 2002;14(4):297-309. 
79. Jordan BA, Devi LA. G-protein-coupled receptor heterodimerization modulates receptor function. Nature. 1999;399(6737):697-700.

80. Trescot AM, Datta S, Lee M, Hansen H. Opioid pharmacology. Pain Physician. 2008;11(2 Suppl):S133-53.

81. Christie MJ. Cellular neuroadaptations to chronic opioids: tolerance, withdrawal and addiction. $\mathrm{Br} \quad \mathrm{J}$ Pharmacol. 2008;154(2):384-96.

82. Bailey CP, Connor M. Opioids: cellular mechanisms of tolerance and physical dependence. Curr Opin Pharmacol. 2005;5(1):60-8.

83. Smith MT. Differences between and combinations of opioids revisited. Curr Opin Anaesthesiol. 2008;21(5):596-601.

84. Kuo A, Wyse BD, Meutermans W, Smith MT. In vivo profiling of seven common opioids for antinociception, constipation and respiratory depression: no two opioids have the same profile. $\mathrm{Br}$ J Pharmacol. 2015;172(2):532-48.

85. Volkow ND, Frieden TR, Hyde PS, Cha SS. Medication-assisted therapies-tackling the opioid-overdose epidemic. N Engl J Med. 2014;370(22):2063-6.

86. Chou R, Turner JA, Devine EB, Hansen RN, Sullivan SD, Blazina I, et al. The effectiveness and risks of long-term opioid therapy for chronic pain: a systematic review for a National Institutes of Health Pathways to Prevention Workshop. Ann Intern Med. 2015;162(4):276-86.

87. Pergolizzi J, Boger RH, Budd K, Dahan A, Erdine S, Hans G, et al. Opioids and the management of chronic severe pain in the elderly: consensus statement of an International Expert Panel with focus on the six clinically most often used World Health Organization Step III opioids (buprenorphine, fentanyl, hydromorphone, methadone, morphine, oxycodone). Pain Pract. 2008;8(4):287-313.

88. Chou R, Weimer MB, Dana T. Methadone overdose and cardiac arrhythmia potential: findings from a review of the evidence for an American Pain Society and College on Problems of Drug Dependence clinical practice guideline. J Pain. 2014; 15(4):338-65.

89. Mercadante S, Ferrera P, Villari P, Casuccio A. Opioid escalation in patients with cancer pain: the effect of age. J Pain Symptom Manage. 2006;32(5):413-9.

90. Papaleontiou M, Henderson CR Jr, Turner BJ, Moore AA, Olkhovskaya Y, Amanfo L, et al. Outcomes associated with opioid use in the treatment of chronic noncancer pain in older adults: a systematic review and meta-analysis. J Am Geriatr Soc. 2010;58(7):1353-69.

91. Reid MC, Eccleston C, Pillemer K. Management of chronic pain in older adults. BMJ. 2015;350:h532.

92. Vadivelu N, Hines RL. Management of chronic pain in the elderly: focus on transdermal buprenorphine. Clin Interv Aging. 2008;3(3):421-30.

93. Dahan A, Yassen A, Romberg R, Sarton E, Teppema L, Olofsen $\mathrm{E}$, et al. Buprenorphine induces ceiling in respiratory depression but not in analgesia. Br J Anaesth. 2006;96(5):627-32.

94. Solomon DH, Rassen JA, Glynn RJ, Lee J, Levin R, Schneeweiss $\mathrm{S}$. The comparative safety of analgesics in older adults with arthritis. Arch Intern Med. 2010;170(22):1968-76.
95. Baron R, Mayoral V, Leijon G, Binder A, Steigerwald I, Serpell M. $5 \%$ lidocaine medicated plaster versus pregabalin in postherpetic neuralgia and diabetic polyneuropathy: an open-label, non-inferiority two-stage RCT study. Curr Med Res Opin. 2009;25(7):1663-76.

96. Davies PS, Galer BS. Review of lidocaine patch $5 \%$ studies in the treatment of postherpetic neuralgia. Drugs. 2004;64(9):937-47.

97. Rowbotham MC, Davies PS, Verkempinck C, Galer BS. Lidocaine patch: double-blind controlled study of a new treatment method for post-herpetic neuralgia. Pain. 1996;65(1):39-44.

98. Wasner G, Kleinert A, Binder A, Schattschneider J, Baron R. Postherpetic neuralgia: topical lidocaine is effective in nociceptor-deprived skin. J Neurol. 2005;252(6):677-86.

99. Casale R, Mattia C. Building a diagnostic algorithm on localized neuropathic pain (LNP) and targeted topical treatment: focus on $5 \%$ lidocaine-medicated plaster. Ther Clin Risk Manag. 2014;10:259-68.

100. Mick G, Correa-Illanes G. Topical pain management with the $5 \%$ lidocaine medicated plaster-a review. Curr Med Res Opin. 2012;28(6):937-51.

101. Sluka KA, Walsh D. Transcutaneous electrical nerve stimulation: basic science mechanisms and clinical effectiveness. J Pain. 2003;4(3):109-21.

102. Weiner DK, Rudy TE, Glick RM, Boston JR, Lieber SJ, Morrow LA, et al. Efficacy of percutaneous electrical nerve stimulation for the treatment of chronic low back pain in older adults. J Am Geriatr Soc. 2003;51(5):599-608.

103. Reisner L. Pharmacological management of persistent pain in older persons. J Pain. 2011;12(3 Suppl 1):S21-9.

104. Cherny NI. The treatment of neuropathic pain: from hubris to humility. Pain. 2007;132(3):225-6.

105. Dib-Hajj SD, Waxman SG. Translational pain research: lessons from genetics and genomics. Sci Transl Med. 2014;6(249):249sr4.

106. Waxman SG, Merkies IS, Gerrits MM, Dib-Hajj S, Lauria G, Cox JJ et al. Sodium channel genes in pain-related disorders: phenotype-genotype associations and recommendations for clinical use. Lancet Neurol. 2014;13(11):1152-60.

107. Dib-Hajj SD, Binshtok AM, Cummins TR, Jarvis MF, Samad T, Zimmermann K. Voltage-gated sodium channels in pain states: role in pathophysiology and targets for treatment. Brain Res Rev. 2009;60(1):65-83.

108. Kirchheiner J, Brosen K, Dahl ML, Gram LF, Kasper S, Roots I, et al. CYP2D6 and CYP2C19 genotype-based dose recommendations for antidepressants: a first step towards subpopulation-specific dosages. Acta Psychiatr Scand. 2001;104(3):173-92.

109. Stamer UM, Zhang L, Book M, Lehmann LE, Stuber F, Musshoff F. CYP2D6 genotype dependent oxycodone metabolism in postoperative patients. PLoS One. 2013;8(3):e60239.

110. Gan SH, Ismail R, Wan Adnan WA, Zulmi W. Impact of CYP2D6 genetic polymorphism on tramadol pharmacokinetics and pharmacodynamics. Mol Diagn Ther. 2007;11(3):171-81. 